\title{
Las formas de Estado en Colombia vistas a través de su historia constitucional.
}

\section{State forms in Colombia seen through constitutional history.}

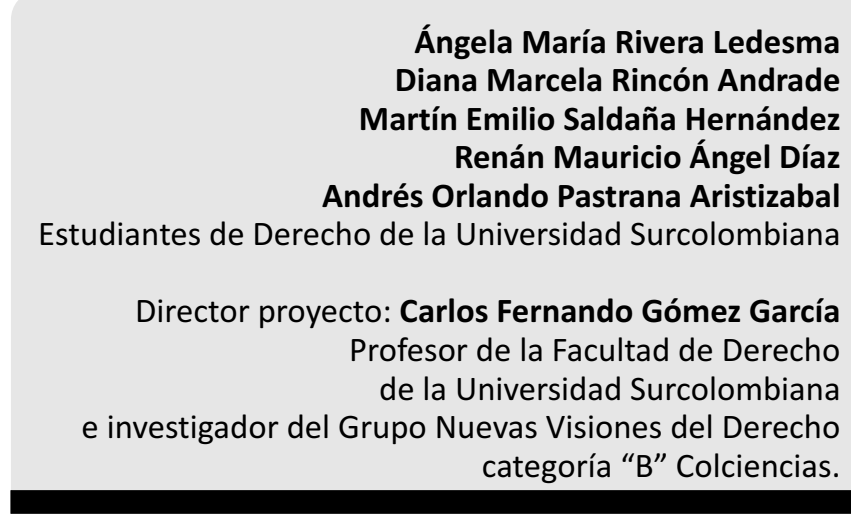

Recibido: 28/03/2012 Aprobado: 04/07/2012

carlos.gomez@usco.edu.co

\section{RESUMEN}

La independencia nacional fue sin duda el primer paso que dio la historia constitucional colombiana hacia su nacimiento, pues siendo Colombia un país independiente debía existir el Contrato Social para la consolidación efectiva del Estado con los derechos y libertades de cada uno de sus integrantes. Con ocasión del Bicentenario de la independencia de Colombia, es una obligación de la academia consolidar los procesos de evolución del Estado colombiano en todos sus ámbitos. La concepción de Estado que existe hoy en día a la luz de la Constitución Política de Colombia de 1991, ha sido una evolución donde el concepto del mismo, concebido como Estado social de Derecho, es el fruto de intentos fallidos de hallar la forma de Estado más pertinente para Colombia, que ha sufrido variaciones en sus instituciones políticas y numerosos intentos de organizarse a través de constituciones.

La historia Constitucional muestra la evolución que ha tenido el país en dicha materia, y aunque la Iglesia Católica, la violencia y la lucha por el poder han sido protagonistas activos desde la época de la independencia hasta la actualidad, la consolidación del derecho constitucional colombiano no es una quimera, por el contrario el fortalecimiento del mismo con el correr de los tiempos ha sido su característica principal.

Así las cosas, el derecho constitucional ha tratado de dar forma al Estado colombiano. De principios monárquicos, en menos de cien años se pasó a ser una república democrática con un sistema de gobierno presidencialista y en menos de doscientos años, un Estado Social de Derecho. Y aunque la democracia ha sido duramente golpeada por fenómenos sociales ya mencionados y políticos, como el Frente Nacional, el derecho constitucional ha salido avante y se ha impuesto sobre los obstáculos que la historia ha mostrado.

En ese orden de ideas, el presente trabajo permitirá conocer a grandes rasgos, la historia del derecho constitucional, las características constitucionales que ha tenido desde 1810 hasta 1886 así como diferentes 
fenómenos sociales, políticos y económicos que influyeron en el desarrollo y evolución del Estado colombiano y su Carta Fundamental.

\section{PALABRAS CLAVE}

Constitución, historia constitucional colombiana, reforma, Colombia, poder.

\section{ABSTRACT}

The national independence was undoubtedly the first step for the birth of the Colombian constitutional history, then Colombia's being an independent country had to have a Social Contract for the effective consolidation of the State with the rights and freedoms of each of its members. To mark the bicentenary of the Colombia's independence, for the academy is an obligation to consolidate the processes of evolution of the Colombian State in all areas. The conception of State that we have today in order to the Colombia's Constitution of 1991, has been an evolution where the concept of it, has been conceived as the Social State of Law is the result of failed attempts to find a way to State more appropiate for Colombia, which has undergone changes in its institutions, policies and organized a lot of attempts through constitutions.

Constitutional history shows us the evolution that has taken our country in this matter, and although the Catholic Church, the violence and the struggle for power have been active participants since the time of independence until today, the consolidation of the Colombian Constitutional Law is not an illusion, otherwise the strengthening of that with the passage of time has been its main feature.

So, our constitutional law has tried to shape the Colombian State, of monarchical principles in less than one hundred years we became a democratic republic with a presidential system of government, and in less than two hundred years we became a Social State of Law. And although democracy has been received hards hits from social phenomena mentioned above, and politicians hits like the National Front, our constitutional law has gone ahead and imposed on the obstacles that history teaches us.

In that meaning, this job will enable you to know in general the history of our constitutional law, the constitutional features that we have had from 1810 to 1886 and various social phenomena, political and economic factors that influenced the development and evolution of our country and its Constitution.

\section{KEYWORDS}

Constitution, Colombian Constitutional History, Reform, Colombia, Power. 


\section{INTRODUCCIÓN}

La aplicabilidad y el efectivo cumplimiento de la norma de normas en un Estado como el colombiano, es una discusión que siempre se ha dado, desde las más altas esferas del gobierno central hasta la pequeña empresa privada, desde la no respuesta a peticiones formales, hasta la violación del derecho a la vida. Se atenta contra lo consagrado en la Carta Política y más aún contra la persona como tal, la violación de los derechos fundamentales, y de los principios y valores constitucionales es una realidad del día a día en Colombia.

El derecho constitucional en Colombia se ha vigorizado con el transcurso de los tiempos, pero en cuanto a su contenido y la forma en que se estructura el Estado, el efectivo cumplimiento de los postulados constitucionales, principalmente los derechos fundamentales, se está lejos de llegar a lo que consagra la Constitución. A pesar de ello, no se puede negar que actualmente los mecanismos de protección de los derechos consagrados en la Carta Política de 1991 superan ampliamente los establecidos en países desarrollados. La acción de tutela y el hábeas corpus son sin duda un medio efectivo de amparo de derechos fundamentales.

La idea de una norma superior que determine la sistematización del Estado, su funcionamiento político, social, económico y cultural, tratando de plasmar la realidad social en una norma jurídica, es imprescindible, pero también lo es su aplicación y el respeto que por la misma deben tener los nacionales.

La evolución de las constituciones nacionales desde la época independentista han sido producto de la necesidad de hallar la forma de Estado y el sistema de Gobierno más conveniente para el país. De igual manera, la necesidad de plasmar en una norma jurídica superior los intereses del pueblo colombiano de acuerdo a cada uno de los contextos históricos y las realidades sociales de las diferentes épocas.

El presente proyecto se trazó el objetivo general de identificar el fundamento teórico e ideológico de las constituciones de Colombia desde 1810 hasta la
Constitución de 1886, en cuanto a la forma de Estado. En este mismo orden de ideas y correspondiendo al objetivo general, se plantearon los siguientes objetivos específicos: identificar las formas de estado generales en la historia constitucional general; identificar las Constituciones Políticas de Colombia que han existido desde 1810; y finalmente analizar las mismas a la luz de la doctrina existente en cuanto a las formas de estado, con una metodología analítico-descriptiva pues comprendió la descripción, registro, análisis e interpretación de datos relacionados con las distintas formas de Estado que han existido en Colombia.

\section{REVOLUCIÓN DE INDEPENDENCIA}

El proceso insurreccional que se desarrollaba en Hispanoamérica en el Siglo XVIII llegó a la Nueva Granada con la Revolución Comunera iniciada en 1781, y la cual se considera como un paso en la independencia colombiana, pues el movimiento comunero no fue otra cosa que el disgusto del pueblo por el mal gobierno español y las aspiraciones de participación política de los criollos.

Con la revolución de independencia de 1810 se quiso institucionalizar un gobierno civil, con un sistema de gobierno federativo, basado en principios constitucionales y republicanos, garantizando la autonomía política de las provincias. La primera Constitución Política se expide en 1811, redactada por Jorge Tadeo Lozano quien se basó en el modelo norteamericano, y la misma contenía principios monárquicos y republicanos. Durante esta época, y hasta 1815 las provincias se dieron sus propias constituciones, destacándose las de Antioquia, Tunja, Cartagena, Mariquita y Neiva, tiempo que fue de valiosa reflexión intelectual en torno a principios constitucionales. (Olano, 2007).

\section{LAGRAN COLOMBIA}

Consolidada la Independencia Nacional con el triunfo en la batalla del Puente de Boyacá. El 12 de Febrero de 1819 se instala el Soberano Congreso de Venezuela que dictó la Ley Fundamental de la República de Colombia, estatuto sancionado el 17 de 
Diciembre de 1819 que unía en una sola república las provincias de Venezuela y la Nueva Granada, de la misma manera se eligió a Bolívar presidente y a Francisco Antonio Zea como vicepresidente.

La Constitución de Cúcuta de 1821 fue expedida en la ciudad del mismo nombre por el Congreso General de Colombia, con influencias de la Constitución española adoptada en Cádiz en 1812, incorporando un gran sentimiento civilista de reflexión constitucional, reafirmando la independencia, señalando que la soberanía reside esencialmente en la Nación y eliminando de manera progresiva la esclavitud. (Liévano, 2004).

Con el ánimo de reformar la Constitución de Cúcuta, se reúnen en Ocaña en 1828 los constituyentes, pues a juicio de los mismos, la Constitución de 1821 estaba obsoleta, sin embargo, las ideas centralistas preconizadas por los bolivarianos y las federalistas por los santanderistas, llevaron al fracaso dicha convención.(Olano, 2007).

Vale la pena señalar la visión que uno y otro tenían del Estado. Por un lado se encontraba Santander, quien pretendía despersonalizar el Estado, creando instituciones que representarían los poderes estatales, dándole autonomía a las regiones, y contando con las opiniones de Venezuela y Ecuador que no gustaban de la excesiva centralización que en Bogotá se percibía. Abogaba por el respeto a la propiedad privada y los derechos accesorios, como por ejemplo, el de contratar autónomamente.

Por otra parte, Bolívar proponía un régimen presidencialista, un Estado autoritario y central. Asociaba la libertad con la igualdad, ordenaba por igual la manumisión de los esclavos y la restitución a los indígenas de sus resguardos.

Bolívar, con una inferioridad numérica de partidarios (diecinueve frente a cincuenta y cuatro santanderistas), decide retirarse de la convención, saliendo de la ciudad con su grupo, dejando sin quórum la reunión y haciendo que esta no se pueda seguir llevando a cabo. Fue así como Bolívar expidió el decreto orgánico que sirvió de Ley Fundamental desde el 27 de agosto de 1828 hasta 1830, quedando sin vigor la Constitución de 1821. Esta norma suprimió el Congreso y la mayoría de sus atribuciones pasaron a manos del Consejo de Estado, por otro lado al jefe del ejecutivo se le daban amplios poderes y funciones.

A pesar de ello, y con el ánimo de superar la crisis de la Constitución de Cúcuta y poner fin al Decreto Orgánico de 1828 que instauro la dictadura, el propio Simón Bolívar instalo en Bogotá el Congreso Admirable, presidido por el Mariscal Sucre, "Fruto de este Congreso fue la Constitución Política de 1830 mediante la cual se efectuaron enmiendas fundamentales, como la de romper el rigorismo del centralismo exagerado, pero sin llegar al federalismo total. Se concibió un centralismo limitado, un campo de acción más amplio en las entidades regionales 0 municipales, dándose así una mayor amplitud a la vida seccional" (Younes, 2007).

\section{LANUEVAGRANADA}

Una vez disuelta la Gran Colombia, en 1832 se expide la Constitución de la Nueva Granada, consagrando un sistema de gobierno popular, federal y representativo. Se limitaron los poderes al jefe del ejecutivo que fueron vistas por muchos como grandes debilidades, la rama legislativa fue bicameral, la del Senado y la de los Representantes, donde los centralistas y la Iglesia Católica empezaron a conocerse como los conservadores y los federalistas como los liberales, y en cuanto a la rama judicial, se procuró por vigorizar su independencia. (Olano, 2007).

Con esta constitución, se abre paso al constitucionalismo colombiano, con una coexistencia de tendencias, como la tesis del origen contractualista y popular del Estado, con el teocentrismo, con Dios como supremo legislador del Universo, aparece la nacionalidad tal y como la conocemos hoy en día, la única diferencia es que al persistir la esclavitud, esta constituía un impedimento para ser nacional, sin embargo como había manumisión de nacimientos, 
los hijos de las esclavas nacidos en el territorio de la Nueva Granada si eran nacionales de nacimiento, cosa diferente era con la ciudadanía y el derecho al sufragio, pues se reservaba para los hombres, casados o mayores de 21 años que supieran leer $y$ escribir, y con la subsistencia asegurada.

Aparecen derechos y garantías, tales como la igualdad ante la ley, de carácter más bien formal por lo que se precisó anteriormente, se consagra el hábeas corpus, la irretroactividad de la ley penal, la libertad de expresión, la inviolabilidad del domicilio y de correspondencia. El territorio se dividía en provincias, con un gobernador dependiente del ejecutivo cuyo periodo duraría cuatro años, cantones, dirigidos por un funcionario designado por el gobernador, y distritos parroquiales. Existía un sistema de elecciones indirecto, es decir, se votaba para elegir los miembros de una asamblea electoral que a su vez se encargaba de elegir al presidente y al vicepresidente de la Republica. (Garzón, 2010).

\section{LACONSTITUCIÓN DE 1843}

Como antecedente a la constitución de 1843 , se tiene la Ley de Policía de 1841, adicionada por la ley de 1842, creada debido a la preocupación que el orden público suscitaba en vista de la sangrienta revolución de los supremos. Este fue el primer conflicto interno en la Colombia independiente y tuvo orígenes religiosos, pues el presidente de la época José lgnacio Márquez ordeno suprimir los conventos que albergaran a menos de ocho religiosos ubicados en Pasto, ello llevo a que líderes religiosos se revelaran con el apoyo del pueblo y a que caudillos del sur opositores al gobierno central, se aprovecharan de tal situación e iniciaran la revolución de los supremos, como ellos mismos se denominaban. Reclamaron independencia de Bogotá en rechazo al centralismo y pronto el conflicto se extendió a otras regiones, incluido un conflicto fronterizo con Ecuador. (Moreno, 2010).

La restricción que tenía el ejecutivo para actuar con eficiencia y prontitud frente a los riesgos que se podían presentar eventualmente fue otro detonante para la expedición de la Ley mencionada. Como principal tarea de la policía se establece la de velar por la tranquilidad y el orden público, mediante la vigilancia, descubrimiento y persecución de posibles conspiradores o de personas que pretendan alterar el orden; la segunda labor es la seguridad pública, luego deben cumplir también con labores de policía judicial, deben también velar por la salubridad general, velar por la decencia y las buenas costumbres, entre otras.

Esta ley afecta de manera sustancial la estructura del poder público, por lo que era necesaria una reforma a la Constitución de 1832, la cual por su complejidad, terminaría convirtiéndose en una nueva constitución. Fundamentalmente centralista y de origen conservador, esta constitución es considerada por muchos como monárquica, pues concedió al Presidente de la República poderes permanentes para superar incluso situaciones de anormalidad. Sin embargo, en ella se amplía la ciudadanía, se organiza el sistema electoral, le reducen poderes al Congreso, se disminuyen los requisitos para poder ser elegido presidente, suprime el Consejo de Estado, se mantiene en cabeza del Congreso la competencia para interpretar y reformar la constitución, y se garantizan los derechos individuales.

\section{LACONSTITUCIÓN DE 1853}

Esta Constitución es sancionada el 21 de Mayo de 1853 y consagra a Colombia como una República democrática, libre y soberana.

Señala algunas libertades, derechos y garantías políticas, como la libertad individual, la seguridad personal, indica que no se puede ser juzgado ni penado por comisiones especiales sino por jueces naturales, la inviolabilidad de la propiedad privada, la libertad de industria y trabajo, la profesión de la religión, la inviolabilidad del domicilio, y en esta se incluye el respeto a la correspondencia privada y a los papeles particulares, la expresión libre del pensamiento sin limitación alguna, el derecho a la reunión, libertad de enseñanza y aprendizaje, la igualdad, el juicio por jurados, se suprime la 
esclavitud, se le reconocen los derechos a los extranjeros, entre otros. (Marquardt, 2011).

El ejecutivo continúa en cabeza del Presidente de la República, facultándosele para celebrar tratados con Venezuela y Ecuador y así lograr el restablecimiento de la unión colombiana bajo un sistema federal. Se avanzó en el proceso de descentralización de la administración, cada provincia disponía lo conveniente a su organización, régimen y administración propia sin invadir las competencias del gobierno central. Así, y con la descentralización política imperante el federalismo gano terreno al punto de que las provincias se dieron sus propias constituciones.

El poder legislativo se constituye en dos cámaras, la de los senadores y los representantes, elegibles para un periodo de dos años y reelegibles indefinidamente.

El poder judicial estuvo encabezado por la Corte Suprema de Justicia, cuyos magistrados eran elegidos popularmente para un periodo de cuatro años.

\section{LACONFEDERACIÓN GRANADINADE 1858}

La Constitución de 1858 creó la Confederación Granadina reorganizando el Estado con un régimen federal. La expedición de algunas leyes en el año de 1859 hicieron que el gobernador el Cauca, general Tomas Cipriano de Mosquera se alzará en armas contra el gobierno central, pues a su juicio las mismas habían desecho el pacto de la federación y violentado la soberanía de las provincias. (Marquardt, 2011).

El triunfo del general Tomas Cipriano de Mosquera dio lugar a la Convención de Rionegro, donde se expediría una nueva Constitución.

\section{LACONSTITUCIÓN DE 1863}

Creada en la Convención de Rionegro, con un claro sistema Federal, la Constitución de 1863 estableció un Estado más laico en cuyo preámbulo se reza: "La Convención Nacional, en nombre y por autorización del Pueblo...", en la cual los Estados Soberanos de Antioquia, Bolívar, Boyacá, Cauca, Cundinamarca, Magdalena, Panamá, Santander y Tolima, se encuentran unidos con un solo nombre, "Estados Unidos de Colombia", con un gobierno republicano, federal, electivo, alternativo y responsable, y un Estado de Derecho, en el que las autoridades de cada uno de los Estados tienen el deber de cumplir y hacer que se cumplan y ejecuten la Constitución y las leyes de la Unión, los decretos y órdenes del Presidente y los mandamientos de los Tribunales y Juzgados, con la división tripartita del poder, finalmente en esta Constitución cada Estado podía elaborar su propia constitución, además de cada uno, tener su propio ejército y el mandato presidencial quedó reducido a dos años, lo cual hizo que el poder legislativo pasara a tener mayor poder que el ejecutivo.(Olano, 2007).

\section{LACONSTITUCIÓNDE 1886}

En Colombia como lo relata Olano (2007) en su libro Constitucionalismo histórico, después de la victoria el presidente electo Rafael Núñez anuncia que "La Constitución de Rionegro ha dejado de existir" (p. 198) y se dispone a encontrar el camino para la expedición de la nueva Constitución.

Las personas encargadas de esta labor no fueron elegidas popularmente, pues de cada estado Soberano se designaron a dos (2) representantes para que participaran como delegatarios y el 5 de agosto de 1886 "En nombre de Dios, fuente suprema de toda autoridad, los delegatarios de los Estados Colombianos de Antioquía, Bolívar, Boyacá, Cauca, Cundinamarca, Magdalena, Panamá, Santander y Tolima, reunidos en Consejo Nacional Constituyente"', proclamaron la nueva constitución Política de la República de Colombia, cuyo cambio de un Estado federado a un Estado centralista, confesional y consagrado al apego de las leyes. Pese a que en el texto de la Constitución Política de Colombia de 1886,

1.- Aparte del preámbulo de la Constitución Política de Colombia de 1886. 
no existía ningún acápite donde explícita-mente se mencionara el Estado de Derecho, pero la estricta división de poderes y el "legicentrismo" hacen deducir eso, además de que solo existía un tribunal de control de legalidad y no de constitucionalidad. Esta Constitución, tenía cuatro (4) rasgos fundamentales como lo menciona Olano (2007) en su libro Constitucionalismo Histórico, restablecimiento de la unidad nacional, libertad de la Iglesia Católica, libertades individuales, robustecimiento del principio de autoridad, todas y cada una de estas características, contenidas y reforzadas por el cuerpo completo que formó la Constitución Política de 1886.

En términos generales los postulados esenciales de la Constitución de 1886, son los tenidos en cuenta al momento de definir históricamente el ámbito o campo de acción en el que se desarrolla un Estado de Derecho. Las obligaciones y los caminos claros por lo que debe actuar un gobernante y los gobernados, la estructura organizacional del mismo estado, divido por poderes o por ramas del poder, que protege y se enmarca dentro de la legalidad del actuar político, nada por fuera de la ley", que impone normas para corregir y sancionar las faltas, que "busca garantizar el respeto de los Derechos Fundamentales de los individuos por encima de todas las demás normas" (Molina et al, 2009, p. 329), son características que encontramos muy marcadas y siempre presentes al momento de realizar una lectura tanto académica, como jurídica de la Carta Política de Colombia de 1886

\subsection{El Concordato de 1887}

Como la Carta de 1886 establecía nuevamente relaciones entre la Iglesia Católica y el Estado Colombiano, la nación designó como su Plenipotenciario ante la Santa Sede a Joaquín Fernando Vélez, quien procedió en 1887, el 31 de diciembre, a firmar con el Secretario de León XIII, el cardenal Rampolla, el Concordato que duró vigente hasta el 12 de julio de 1973, cuando se firmó el nuevo, que fue declarado parcialmente inexequible por la Corte Constitucional en la Sentencia C-027 de 1993.

\subsection{Las reformas constitucionales del siglo XX}

Dentro de las múltiples y variadas reformas, inspiradas en diferentes corrientes e ideologías políticas y filosóficas, realizadas a la Constitución Nacional de 1886, se abordará en el estudio de un selecto grupo que a juicio del investigador permitirá establecer ideas claras sobre las formas y modelos de Estados que agrupan el periodo de tiempo regido por esta constitución; ya que en tratándose de identificar las fuentes que han dado lugar al Estado Social de Derecho son las que han materializado la transición de una forma de Estado a otra.

\subsection{Del periodo de Reyes}

El General RAFAEL REYES asumió la jefatura del Estado colombiano en 1904 cuando la situación del país no era sencilla. En primer lugar, en el año 1903, se produce la separación de Colombia con el territorio que hoy toma el nombre de Estado de Panamá, dando paso a un profundo sentimiento antinorteamericano y; en segundo lugar, la paupérrima situación en que queda el país después de la guerra de los Mil días, le obligo a fijar como puntos centrales de su administración: la creación de Rentas o Impuestos, el pago de la deuda y la aplicación inmediata de recursos que se pudieran obtener. (Olano, 2007).

En el mismo año en que el General Reyes se posesiona como primer mandatario del Estado Colombiano el congreso NO expide la ley de presupuestos y gastos, norma relevante para el funcionamiento del aparato estatal. Por lo anterior, el presidente expidió los decretos necesarios, según su juicio, para arreglar la mencionada situación que había dado lugar a la crisis.

Con el fin de que se pudiera conocer el contenido de los Decretos expedidos por el presidente se convoca a una Asamblea Nacional Constituyente que se reuniría el 15 de Marzo de 1905 en la ciudad de Bogotá y que tendría funciones legislativas de cuerpo constituyente, siendo sus facultades las que la Constitución reconocían al congreso en sesiones 
extraordinarias.(Olano, 2007).

En ese orden de ideas, dicha Asamblea profirió diez (10) Actos legislativos en un lapso de cuatro (4) días, del 27 al 30 de Abril de 1905. El primero de los actos legislativos con tan solo 3 artículos, hacía referencia sobre el periodo de los Magistrados de la Corte Suprema de Justicia y de Tribunales Superiores del Distrito Judicial determinándolo en un lapso de 5 años que empezaría a correr el 1 de mayo y 1 de Junio de la anualidad, respectivamente.

El segundo, establece el cronograma de reunión de las cámaras legislativas fijándolo en cada dos años, el día 1 de febrero en la capital de la república. Así mismo establece que las sesiones ordinarias duraran noventa días. Y por último, la Asamblea Nacional Constituyente establece que el primer congreso constitucional instalado bajo las reglas antes descritas se reunirá el 1 de febrero de 1908, casi dos años después de haberse establecido la Asamblea.

Con base en lo anterior, la Asamblea Nacional convocada por el Presidente Rafael Reyes se atribuye las funciones que por mandato constitucional son naturales del congreso (entiéndase senado y cámara).

El tercer Acto legislativo se ocupa de manera importante de la división política del territorio nacional con el fin de mejorar la administración pública del Estado. En este sentido, se establece que la Ley podrá alterar la división territorial formando los departamentos que considere necesarios, además podrá crear Distritos para que se rijan por leyes especiales. Y con base en la división que se haga, se podrán distribuir bienes y cargas, el número de senadores y representantes y su forma de elegirlos.

El siguiente Acto, deroga de forma expresa el artículo 5 de la Constitución Nacional de 1886 al suprimir el cargo de vicepresidencia de la Republica y su facultad para ser designado para ejercer el poder ejecutivo. Como consecuencia de lo anterior, cuando existiere una falta absoluta del presidente de la
Republica se deberá reunir el Consejo de Ministros para que designe uno de ellos que lo reemplace y si faltaren los ministros el gobernador del departamento más cercano, nombrado este suplente, su función principal es convocar a la Asamblea Nacional o en su defecto al Congreso dentro de los sesenta días siguientes a su nombramiento para que sea elegido presidente para lo que resta del periodo. (Esguerra, 2010).

Es importante hacer hincapié en la introducción del artículo quinto (5) del Acto Legislativo en mención, pues éste fija el periodo presidencial del General Rafael Reyes en un lapso de 10 años que culminarían el 31 de Diciembre de 1914, así como reduce los periodos presidenciales subsiguientes al termino de 4 años.

Es innegable la intención de la Asamblea Nacional Constituyente con la expedición de este Acto Legislativo, pues denota y acentúa el interés de sus miembros de resaltar que el cargo de Presidente de la República es Intuito Personae; es decir, si se elige cierto ciudadano es porque sus calidades académicas, éticas, morales entre otras, inspiran en los ciudadanos la certeza de que cumplirá a cabalidad los cometidos de su cargo.

Las disposiciones de este Acto, sin lugar a dudas, son una respuesta a la reiterada situación presente en este período de la historia colombiana de que "no gobierna quien se elige", pues los partidos políticos de esta época como los conservadores, liberales, nacionalistas, el movimiento de los históricos, proponían fórmulas presidenciales tras las que gobernaba otra persona cuando salían electas 0 terminaba ejerciendo el mandato el vicepresidente de la República, proveyendo ésta conducta inseguridad al Estado.

El siguiente acto legislativo contenía un solo artículo que hacía referencia a que nadie podría ser privado de su derecho de propiedad en tiempos de paz, a excepción de dos casos, la contribución general o motivos de utilidad pública. 
A continuación, se expide otro acto legislativo orientado a establecer como funciones de las Asambleas departamentales, fomentar y dirigir con recursos del Departamento, la instrucción primaria y la beneficencia, las industrias establecidas y la construcción de otras nuevas, colonización de tierras baldías, la apertura de caminos, el arreglo de la policía local y cárceles, así como la fiscalización de rentas y gastos.

El octavo acto legislativo establece que la cámara de representantes y el senado se renovaran al mismo tiempo y en su artículo 4 indica que toda elección popular debe realizarse reconociendo el derecho de representación de las minorías. El noveno acto legislativo, sustituye el artículo 209 de la constitución nacional pues en su articulado instituye la forma en la que podrá ser reformada la constitución, que se hará por Asamblea Nacional, sin embargo, su procedimiento se lleva a cabo como el de cualquiera de las leyes de la república.

Por último, el acto legislativo que cerró la labor de la asamblea nacional constituyente convocada por el Presidente Rafael Reyes suprime el Consejo de Estado e indica que la ley determinará el desarrollo de las funciones de esta corporación por otros empleados del Estado.

Los diez actos legislativos aprobados en 1905 fueron reunidos en un solo acto o instrumento oficial, al que se le dio el nombre de "Acto general adicional y reformatorio de la Constitución Nacional", fechado el 30 de abril de 1905 (Esguerra, 2010).

Es importante hacer mención que el día 29 de abril de 1905, un día antes de la clausura de la Asamblea Nacional, esta misma por mayoría absoluta aprueba la norma que dio participación política a las minorías, manifestándose en los siguientes términos:

"La asamblea nacional constituyente y legislativa consigna en el acta de este día la expresión de la más intima satisfacción por el honor que le ha correspondido de haber consagrado en la Constitución y en la ley, por la primera vez en Colombia, y llevado hoy a la práctica, en la elección de Consejeros Electorales, el principio republicano de la representación de las minorías; y se congratula con el excelentísimo presidente de la república por su rigurosa y eficaz iniciativa en esta patriótica y reparadora labor, que tiende a asegurar la paz, la prosperidad y el engrandecimiento de la nación, con el funcionamiento sosegado y la cooperación simultanea de todos los partidarios de la administración pública." ${ }^{2}$.

Posteriormente, se expidieron dentro de este mismo periodo normas por parte de la Asamblea Nacional orientadas a la organización electoral, división del territorio, inicio e instalación de sesiones en él.

El siete (7) de Junio de 1909 el presidente de la republica Rafael Reyes en lo que tomaría el nombre de "Manifiesto" encarga temporalmente el poder ejecutivo al señor General Jorge Holguín asegurando que volvería al poder cuando las circunstancias de orden público así lo ameritaran. Sin embargo, una vez instalado el congreso Holguín hizo pública su renuncia a la primera magistratura siendo aceptada por el congreso, que se dispondría a proveer el cargo el cual fue tomado por mayoría del senado a Ramón González Valencia.

El nuevo presidente convoca mediante decreto No. 126 del 25 de Febrero de 1910, a una nueva Asamblea Nacional Constituyente para que tratara temas importantes como el restablecimiento de las tradiciones del Derecho público en cuanto al señalamiento de límites del territorio nacional, la división administrativa del territorio, entre otros. (Esguerra, 2010).

Básicamente se hicieron nuevas reformas contenidas en actos legislativos y normas sobre temas abordados en la asamblea nacional constituyente convocada en el gobierno del General Rafael Reyes. 


\subsection{La Reforma Constitucional de 1910}

El acto legislativo No. 3 de 1910, enmarca una profunda reforma constitucional, que luego de cinco (5) años de dictadura con el General Rafael Reyes se vuelve el camino de la democracia.

La Asamblea Nacional Constituyente fue pluralista, en el sentido de haberse conformado con representantes de las dos vertientes políticas en ese entonces, dentro de los más relevantes, se podría destacar que varias de las figuras e instituciones establecidas en esta reforma de 1910 trascendieron en el tiempo como la acción pública de inconstitucionalidad, que fue uno de los grandes aportes al Estado de Derecho.

La entronización de los puntos centrales del acuerdo político que parecía haber entre la mayoría de los partidos políticos de la época reunidos en la Unión Republicana, quienes deberían propiciar por el acatamiento de la constitución nacional de 1886 por parte del liberalismo. Lo anterior, sirvió de cimiento a la necesitada recomposición del Estado de Derecho en el que primara la legalidad, la seguridad jurídica, las libertades públicas y las garantías ciudadanas.

Dentro de los puntos relevantes de esta reforma se puede mencionar, la derogación de buena parte de los Decretos y reformas constitucionales de la dictadura del General Rafael Reyes, la elección popular y directa del presidente de la república, reducción del período presidencial de 6 a 4 años y prohibición de reelección inmediata, reducción de poderes presidenciales y responsabilidad del primer mandatario, se despojó al presidente de la capacidad de celebrar convenios internacionales, se le hizo responsable por violar la constitución y la ley, cuando se declare Estado de sitio el presidente no podrá derogar sino suspender la legislación vigente, los decretos extraordinarios solo rigen hasta que se restablezca el orden público.(Olano, 2007).

El congreso de la Republica escoge los magistrados de la Corte suprema de Justicia, el periodo de los senadores se fija en 4 años, el de los representantes a la cámara en 2 años reelegibles indefinidamente.

Se establece el control de constitucionalidad en cabeza del presidente de las leyes que expedía el congreso; asegurando así un Sistema presidencialista, pudiendo objetar su contenido y devolverlo para que se hiciera la respectiva corrección, pero si el congreso insistía en el texto original se enviaba a la Corte Suprema de Justicia.

Se crea la Jurisdicción contencioso administrativa y el control de legalidad por parte del Consejo de Estado, que reaparece luego de que la Asamblea Nacional Constituyente del gobierno de Rafael Reyes lo hiciese desaparecer.

Se consagran en esta reforma garantías sociales como la suspensión de la pena de muerte, la protección a la propiedad privada, la prohibición de emitir papel moneda de curso forzado. Se instaura la descentralización territorial organizada en departamentos, distritos capitales y municipios; se procede a hacer una delimitación detallada de las fronteras del Estado Colombiano y por último; se consagra como mecanismo de reforma constitucional el Acto legislativo que debía ser aprobado y discutido en tres debates por el congreso en forma ordinaria, transmitido por el Gobierno a la legislatura subsiguiente, y aprobado luego por ésta con dos tercios de los votos de ambas cámaras.(Esguerra, 2010).

\subsection{La Reforma a la Carta Política de 1936}

Tradicionalmente, la reforma constitucional de 1936 en Colombia ha sido encuadrada en el marco de referencia del surgimiento del Estado interventor en el país, e incluso en América Latina. Si bien su temporalidad, su temática y su contexto concuerdan con esta apreciación, recientes estudios dejan en claro que los desarrollos latinoamericanos fueron distintos al modelo clásico -europeo- de Estado interventor, y señalan además que el estudio de la consolidación del Estado en esta región supone desafíos particulares. Uno de tales estudios, la investigación comparativa de Ruth y David Collier, 
propone que los procesos de incorporación de los movimientos obreros al ámbito político nacional en distintos países latinoamericanos constituyen coyunturas críticas que moldearon de diversas maneras las arenas políticas nacionales del continente en el siglo XX y marcaron el proceso de configuración de sus Estados (Botero, 2006).

Es menester describir los hechos más relevantes de este periodo y que dieron lugar al nacimiento de la reforma a la carta política de 1886; pues el arribo del liberalismo al poder luego de una prolongada hegemonía conservadora permitió que el Estado colombiano se permeará de las ideas liberales y de esta forma dentro de un nuevo marco político lograr la renovación del Estado.

Un nuevo escenario de libertad, justicia social, imperio de la norma jurídica, igualdad humana y liberación del yugo de la Iglesia que durante mucho tiempo y con la aquiescencia del gobierno conservador censuraba cualquier conducta que fuera en contravía de sus fundamentos, se establece en el país a partir de 1930 luego de la elección de Enrique Olaya Herrera como presidente de la República.

Unos de los eventos más importantes y que dio el punto de partida a la transformación del Estado fue la expedición de la Ley 200 de 1936 recordada como la Ley de tierras, que logró sustraer los monopolios de los terratenientes, y de esta forma otorgarle un papel preponderante al campesinado como eje del desarrollo rural del Estado Colombiano y darle a los administrados una verdadera justicia material. Con esta Ley empieza a tomar forma el concepto de que la propiedad privada, aún más la rural, debe tener una finalidad social.

El acto legislativo 01 de 1936 desdibujo la figura del Estado - poder por la del Estado - Nación debido a la profunda influencia en sus precursores liberales de las ideas de grandes pensados como León Duguit; de esta forma se migraba hacia una idea de Estado donde la soberanía y la nación se conjugaban para formar la soberanía nacional como un poder de voluntad en el que se abre paso el servicio público.

La reforma, contentiva de 35 artículos, transformó preceptos constitucionales sobre límites geográficos, división territorial, funcionamiento del Congreso, régimen de propiedad privada, ciudadanía y educación. Tal y como lo afirma Botero (2006), la reforma parte de lo que se conoce como "el reformismo lopista", una serie de iniciativas desarrolladas durante el gobierno de este presidente liberal entre las cuales se cuentan también la Ley 200 de 1936 (conocida como "ley de reforma agraria"), una reforma tributaria, y una iniciativa general de reforma del sistema educativo colombiano. El foco de atención está puesto sobre las políticas sociales en la reforma, a sabiendas de que éste es sólo uno de los muchos aspectos que allí se vieron involucrados.

La reforma puede abordarse desde dos puntos de vista, tal y como lo argumenta el investigador Álvaro Tirado Mejía (1982), el primero, es que la reforma es única y exclusivamente fruto de la iniciativa presidencial en cabeza del partido liberal y el segundo, es que dicha reforma es originada por la influencia de muchos factores que dieron como resultado una concepción "social" de las instituciones más importantes del Estado.

Pese a que la posición presentada por Tirado Mejía es la primera de las mencionadas anteriormente, es importante resaltar tal como lo argumenta Cesáreo Rocha Ochoa "se partió del concepto de que el texto constitucional de 1886 era teóricamente admirable en su integridad primitiva, pero es evidente que los hechos sociales y el tiempo recorrido desde entonces a 1936 implicaban la urgente atención a las necesidades del momento" (Rocha, 2010).

Es relevante tener en cuenta que en este lapso de tiempo el continente americano era permeado por ideas de juristas que fueron influencia para plasmar en las nuevas constituciones el concepto de la dignidad humana, que más adelante sería el sustento del Estado Social de Derecho de la constitución política de 1991, los derechos humanos, al trabajo, a la seguridad social, a la lucha contra la discriminación 
de clases, a la igualdad, libertad, desarrollo económico entre otros.

La reforma constitución de 1936 establece un verdadero nuevo orden constitucional, redefinió la carta de derechos configurada en la constitución de 1886 y agregó otros, y más importante aún, impone funciones al Estado que redundan en la protección de los derechos de las personas sometidas a la jurisdicción del mismo y no tan solo la restricción en su actuar como en principio lo consagraba la constitución.

\subsection{La Reforma Constitucional de 1945}

Consagró normas de carácter reglamentarias, concernientes sobre todo en el procedimiento legislativo, le otorgó categoría constitucional a la Contraloría General de la Republica. Pese a que la reforma constitucional de 1936 es considerada pionera en el establecimiento de un Estado Social de Derecho por redimensionar y ampliar la categoría de derechos consagrada en la constitución de 1886, es paupérrima en otorgar mecanismos de protección a los derechos reconocidos. En ese orden de ideas, la reforma constitucional de 1945 realiza grandes aportes para la protección de Derechos, dándole un alcance real y material, y avanzando en el fortalecimiento de un Estado Social de Derecho. Se establece un verdadero funcionamiento del sistema de "pesos y contrapesos" y colaboración armónica de las ramas del Estado, Vgr. Cuando el Congreso mediante ley autoriza al Gobierno Central para realizar 0 intervenir en cierta actividad de interés nacional respetando la propiedad privada y buscando el equilibrio entre el capital y el trabajo. (Olano, 2007).

Establece, una nueva categoría de leyes, teniendo en cuenta el impacto sobre la estructura del Estado y la sostenibilidad económica y política del mismo, fijando como criterio que el Congreso (comprendido por sus dos cámaras y comisiones permanentes respectivas), aprobara una ley con la mayoría absoluta de los votos de sus miembros. Este es el antecedente más claro de la existencia de leyes especiales dentro del Estado colombiano.
Toda norma en sentido material que se expidiera debía fijarse dentro del marco del principio de centralización política y descentralización administrativa, permitiendo de esta forma una verdadera organización territorial pues esto permitió la eliminación de algunos municipios con una cantidad de habitantes mínima mejorando de esta forma la destinación de los recursos fiscales para hacerlos más efectivos.

"En el clásico esquema del Estado Unitario, la reforma del 45 llegó hasta donde era posible en materia de descentralización territorial. Pero fue el primer paso hacia desarrollos más avanzados que logró, medio siglo después, la carta de 1991" (Trujillo, 2010, p. 169).

Teniendo en cuenta lo anterior, esta reforma, incorpora el concepto de autonomía territorial, de esta forma ahonda en la intensión de crear un nuevo modelo de Estado, ya que hace un tránsito de la descentralización territorial a una verdadera autonomía territorial "en términos que desbordan el esquema clásico del Estado Unitario".

\section{CONCLUSIONES}

Colombia no ha sufrido cambios significativos en cuanto a forma de Estado y Sistema de Gobierno, la tendencia desde los inicios de la democracia ha sido entre Centralismo y Federalismo, dándose finalmente un equilibrio, lo que hoy consagra la Constitución, Centralización Política y Descentralización Administrativa. El sistema político siempre se ha inclinado hacia el presidencialismo, con el modelo de pesos y contrapesos de Montesquieu, con un parlamento bicameral integrado por Senado y Cámara de Representantes, y por la Corte Suprema, máximo organismo del poder judicial que complementa la estructura del Estado colombiano.

No se puede pasar por alto el tema de la violencia, tanto la bipartidista que termino con el Frente Nacional, como el conflicto armado suscitado a finales de los años 40. Colombia desde la época de la conquista siempre ha estado en guerra, y esta 
condición ha incidido en las diferentes constituciones, tanto en la expedición, como en los postulados de las mismas.

Existen además otros fenómenos sociales que incidieron en las constituciones colombianas, los ánimos del Estado de cumplir con sus fines esenciales, cambiantes estos en las diferentes épocas de la historia, para tener una sociedad más justa y equitativa, y superar la desigualdad, la pobreza, la esclavitud y todos los problemas de orden económico, social y político, queriendo recomponer el país, dándole nuevos rumbos de acuerdo a las cambiantes circunstancias.

Colombia es un país muy rico en cuanto a constitucionalismo se refiere, se fortaleció con la Constitución Política de 1991 y la creación de la Corte Constitucional, máximo órgano de la rama judicial encargada de la guarda y cumplimiento de la Norma de normas. Sin embargo, aun tiene largos caminos por recorrer, más aun cuando el país empieza a tomar un cambio de mentalidad que va de la mano con la globalización, el internet y la tecnología.

\section{BIBLIOGRAFIA}

- Botero, S. (2006). La reforma constitucional de 1936, el Estado y las políticas sociales en Colombia. Anuario Colombiano de Historia social y de Cultura. Bogotá. Universidad Nacional de Colombia.

- Esguerra, J. (2010). La reforma constitucional de 1910. En Vidal, J. (2010). Historia constitucional de Colombia siglo XX Tomo 2. Bogotá: Ediciones Academia Colombiana de Jurisprudencia.

- Garzón, E. (2010) La convención de Ocaña y la Constitución Política de la Nueva Granada de 1832. En Vidal, J. (2010). Historia constitucional de Colombia siglo XIX Tomo 3. Bogotá: Ediciones Academia Colombiana de Jurisprudencia.

- Liévano, I. (2004). Los grandes conflictos sociales y económicos de nuestra historia. De la campaña libertadora al congreso de Panamá. Bogotá: Intermedio Editores Ltda.

- Marquardt, B. (2011). Los dos siglos del Estado
Constitucional en América Latina (1810 - 2010), Historia Constitucional Comparada. Serie de investigaciones Jurídico - Políticos de la U. Nacional No. 5. Bogotá: U. Nacional de Colombia.

- Marquardt, B. (2011). Los dos siglos del Estado Constitucional en América Latina (1810 - 2010), Historia Constitucional Comparada. Serie de investigaciones Jurídico - Políticos de la Universidad Nacional No. 6. Bogotá: Universidad Nacional de Colombia.

- Mayorga, F. (2010). Las reformas constitucionales del periodo de los reyes. En Vidal, J. (2010). Historia constitucional de Colombia siglo XX Tomo II. Bogotá: Ediciones Academia Colombiana de Jurisprudencia

- Molina, C. Álvarez, M. Peláez, F y Botero, L (2009). Derecho Constitucional General ( $3^{a}$ ed.). Medellín: Sello Editorial Universidad de Medellín.

- Moreno, L. (2010). La segunda constitución de la República de Nueva Granada. En Vidal, J. (2010). Historia constitucional de Colombia siglo XIX Tomo 1. Bogotá: Ediciones Academia Colombiana de Jurisprudencia.

- Olano, H. (2007). Constitucionalismo Histórico. Historia de Colombia a partir de sus constituciones y reformas ( $2^{\mathrm{a}}$ ed.). Bogotá D.C.: Ediciones Doctrina y Ley LTDA.

- Rocha, C. (2010). La reforma constitucional de 1936. En Vidal, J. (2010). Historia constitucional de Colombia siglo XX Tomo 2. Bogotá: Ediciones Academia Colombiana de Jurisprudencia.

- Trujillo, A. (2010). La reforma constitucional de 1945. En Vidal, J. (2010). Historia constitucional de Colombia siglo XX Tomo II. Bogotá: Ediciones Academia Colombiana de Jurisprudencia

- Vidal, J. (2010). Historia Constitucional de Colombia. Siglo XIX. Tomo 1. Bogotá: Ediciones Academia Colombiana de Jurisprudencia

- Vidal, J. (2010). Historia Constitucional de Colombia. Siglo XX. Tomo 2. Bogotá: Ediciones Academia Colombiana de Jurisprudencia

- Vidal, J. (2010). Historia Constitucional de Colombia. Análisis Temáticos. Tomo 3. Bogotá: Ediciones Academia Colombiana de Jurisprudencia

- Younes, D. (2007). Derecho Constitucional Colombiano, Ediciones Jurídicas Gustavo lbáñez, Bogotá 